\title{
TENSILE AND BOND CHARACTERIZATION OF NATURAL FIBERS EMBEEDED IN INORGANIC MATRICES
}

\author{
Bahman Ghiassi $^{1(*)}$, Arezou Razavizadeh ${ }^{2}$, Daniel V. Oliveira ${ }^{3}$, Vera Marques ${ }^{4}$, Paulo B. Lourenço ${ }^{5}$ \\ ${ }^{1}$ Postdoctoral researcher, ISISE, University of Minho, Guimarães, Portugal \\ ${ }^{2} \mathrm{PhD}$ candidate, ISISE, University of Minho, Guimarães, Portugal \\ ${ }^{3}$ Associate professor, ISISE, University of Minho, Guimarães, Portugal \\ ${ }^{4} \mathrm{MSc}$, University of Minho, Guimarães, Portugal \\ ${ }^{5}$ Professor, ISISE, University of Minho, Guimarães, Portugal \\ ${ }^{(*)}$ Email: bahmanghiassi@civil.uminho.pt
}

\begin{abstract}
Innovative composite materials made of continuous fibers embedded in mortar matrices have been recently received attention for externally bonded reinforcement of masonry structures. In this regards, application of natural fibers for strengthening of the repair mortars is attractive due to their low specific weight, sustainability and recycability. This paper presents experimental characterization of tensile and pull-out behavior of natural fibers embedded in two different mortar-based matrices. A lime-based and a geopolymeric-based mortar are used as sustainable and innovative matrices. The obtained experimental results and observations are presented and discussed.
\end{abstract}

\section{INTRODUCTION}

Innovative composite materials made of continuous fibers embedded in mortar matrices have been recently received attention for externally bonded reinforcement of masonry structures. These materials are usually identified as FRCM, TRM, or TRC in the literature. FRCMs are proposed to overcome or reduce the disadvantages related to the use of FRPs such as durability and compatibility with the masonry substrate (D'Ambrisi et al. 2013; de Felice et al. 2014; Carozzi et al. 2014). Mortar based matrices exhibit a significant heat resistance, allows vapor permeability, can be applied either at low temperatures or on wet surfaces, have a better compatibility with masonry substrates and allow for reversibility. The latter is of great importance in case of strengthening of historical structures.

FRCMs are usually constructed with continuous fibers embedded in cementitious mortars. Lime-based mortars are preferable in case of masonry and historical structures as they are more sustainable and compatible with the substrate (de Felice et al. 2014). The fabrics are usually in the form of grids made of multifilament carbon, glass or steel yarns. The use of natural fibers such as flax, hemp and jute has also received interest for strengthening of masonry structures (Codispoti et al. 2013). Application of natural fibers in Civil Engineering applications is attractive due to their low specific weight, sustainability and recycability.

Despite the recent interest on the use of FRCMs for strengthening purposes, information regarding their mechanical performance and long-term durability is still lacking. The performance of FRCM strengthened masonry elements is strongly dependent on the mechanical properties of the FRCM, the bond behavior between the fibers and mortar matrix, and the bond behavior between the mortar and the masonry substrate (Sueki et al. 2007; Carrozi and Pogi 2015). 
This paper presents preliminary results of an experimental campaign aimed at mechanical characterization of FRCMs made of flax natural fibers. The tests include tensile characterization of FRCM composite coupons and pull-out tests for characterization of the fiber/mortar bond behavior. A pozzolanic lime-based and a geopolymeric-based mortar are used as two sustainable and innovative matrices. Tensile tests are performed on flax single yarn, flax fabric and flax fabrics embedded in mortar. Six specimens are prepared and tested for each material model. The pull-out tests are performed on flax fabrics embedded in the mortar with $50 \mathrm{~mm}$ and $100 \mathrm{~mm}$ bonded lengths. Five specimens are prepared for each mortar type and bonded length resulting in total twenty pull-out specimens. The experimental results are presented and discussed.

\section{MATERIALS AND SPECIMENS}

The materials consisted of a commercial pozzolanic lime-based and a geopolymeric-based mortar as the matrix and a commercial bidirectional flax fabric as the reinforcing material.

The specimens consisted of mortar samples for compressive and flexural tests and fiber and fiber reinforced mortar samples for tensile characterization tests. Fiber fabrics embedded in mortar cylinders were also prepared for performing the pull-out tests. The specimens were prepared and stored in the laboratory conditions $\left(20^{\circ} \mathrm{C}\right.$ and $60 \%$ R.H.) for three months before performing the mechanical tests to assure that the mortar was completely cured.

Mortar specimens consisted of cylindrical samples with $50 \mathrm{~mm}$ diameter and $100 \mathrm{~mm}$ height for compressive tests and $40 \times 40 \times 160 \mathrm{~mm}$ prismatic samples for flexural tests, see Fig. 1 . The specimens were prepared according to the specifications provided by EN 1015-11 (2007).

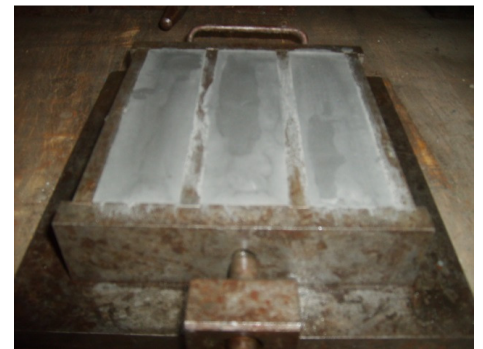

(a)

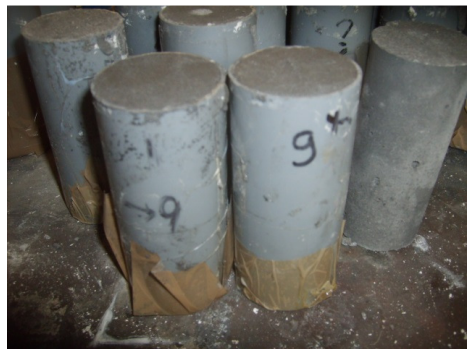

(b)

Fig.1 Mortar specimens: (a) prismatic samples; (b) cylindrical samples.

Fiber specimens consisted of single yarn and fabric samples for tensile characterization tests. The fabric specimens were cut with $50 \mathrm{~mm}$ width and $150 \mathrm{~mm}$ free length, see Fig. 2 . Aluminum tabs were glued at both ends of the specimens for gripping the specimens during the tests. The fiber reinforced mortar specimens were prepared according to the geometrical details shown in Fig. 3.

The geometrical details of the pull-out tests specimens are shown in Fig. 4. Fiber fabrics with $50 \mathrm{~mm}$ width were embedded in the cylindrical mortar specimens with different bonded lengths. Again, an aluminum tab was used at the end of the fabric free end for gripping the specimens. The free length of the fabrics was impregnated with an epoxy resin to avoid unfortunate failure during the tests. Two sets of specimens with different bonded lengths of $50 \mathrm{~mm}$ and $100 \mathrm{~mm}$ were prepared for each mortar type. The cylinder heights were chosen equal to the bonded length according to the details shown in Fig. 4(a). 


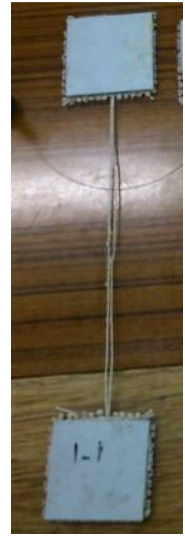

(a)

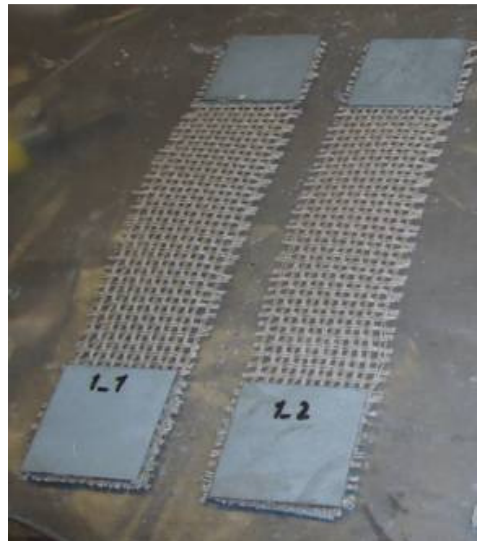

(b)

Fig.2 Specimen details for tensile tests: (a) single yarn; (b) fabric test.

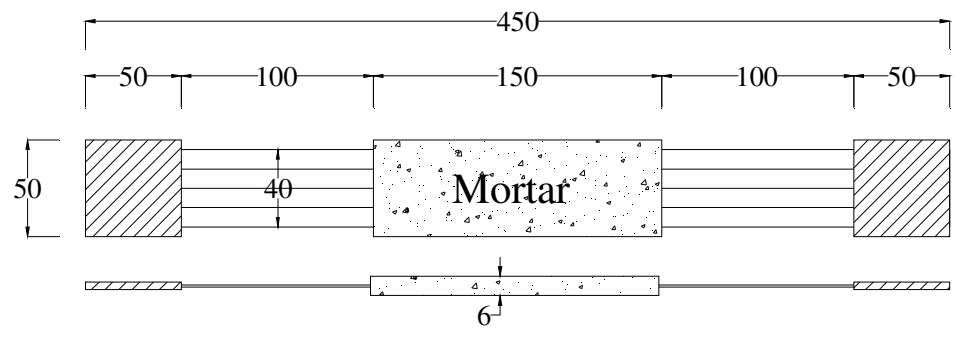

Fig.3 Geometrical details of fiber reinforced mortar specimens.

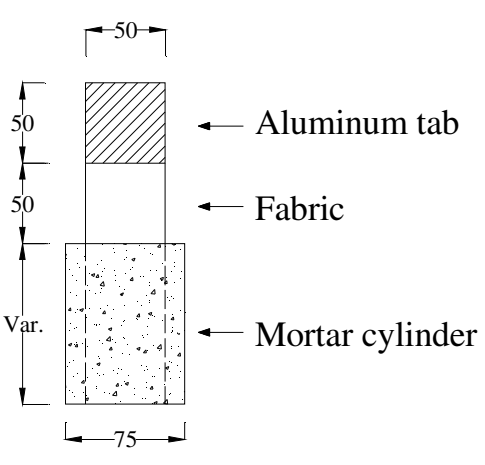

(a)

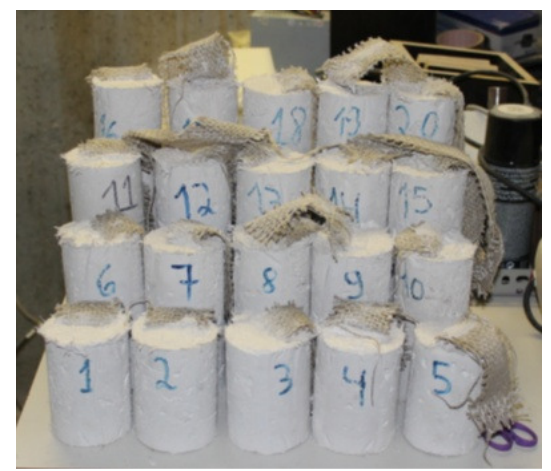

(b)

Fig.4 Pull-out test specimens: (a) geometrical details; (b) specimens.

\section{TEST METHODS}

The tests included compressive and flexural tests on mortar specimens, direct tensile tests on single flax yarns, flax fabric and fiber reinforced mortar specimens and fiber pull-out tests. The mortar compressive and three-point bending tests were performed after three months of curing in the laboratory conditions according to EN 1015-11 (2007). The tests were performed by means of a universal testing machine under force controlled conditions, see also Fig. 5. 


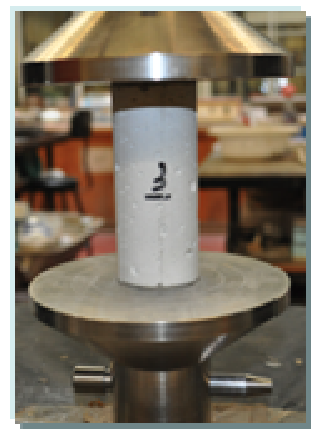

(a)

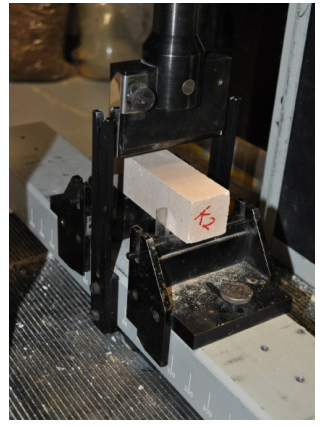

(b)

Fig.5 (a) Compressive tests on mortar cylinders; (b) three-point bending tests.

The tensile tests were performed on single flax yarn, flax fabric and fiber reinforced mortar specimens by means of a universal testing machine, see Fig. 6 . All the tests were performed under displacement control conditions at the rate of $2 \mathrm{~mm} / \mathrm{min}$ so that the results will be comparable. The applied load was recorded by a load cell integrated in the testing machine, while deformation was monitored by a clip gauge placed on the middle of the specimens.

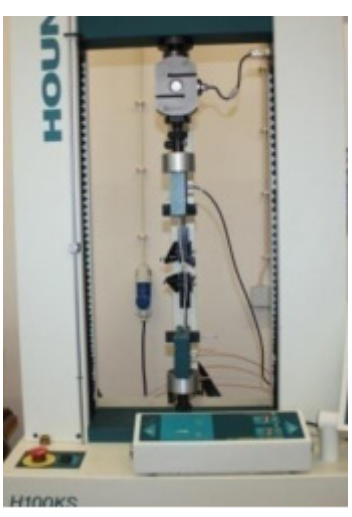

(a)

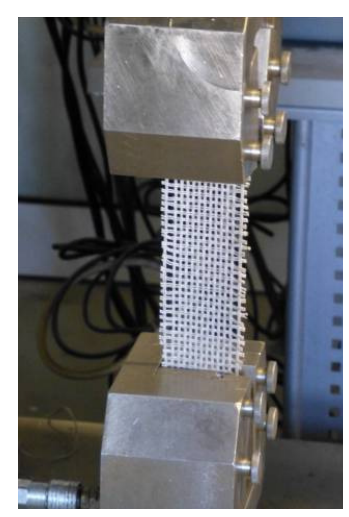

(b)

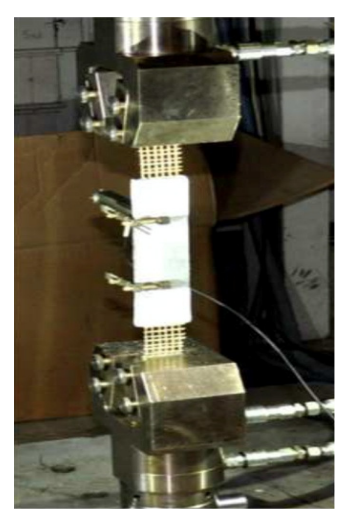

(c)

Fig.6 Tensile tests setup: (a) single yarn tests; (b) fabric test; (c) FRCM test.

Fiber pull-out tests were performed to characterize the bond behavior between flax fabrics and mortars. The specimens were fairly clamped to a supporting frame to avoid any movement during the tests, see Fig. 5. The fabrics were pulled from the mortar monotonically with a velocity of $0.3 \mathrm{~mm} / \mathrm{min}$. The tests were driven under displacement control using a LVDT placed at the loaded end of the flax fabric. The resulting load was measured by means of a load cell.

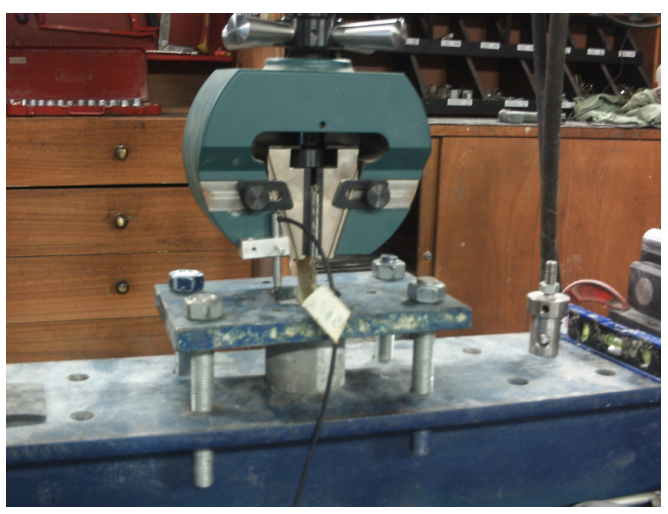

Fig.7 Pull-out test setup 


\section{RESULTS AND DISCUSSION}

\section{Mortar properties}

The mechanical properties of the mortars are listed in Table 1 and Table 2. It can be observed that the lime-based mortar has a compressive strength of $12.7 \mathrm{MPa}$, almost two times larger than the geopolymeric-based mortar $(6.5 \mathrm{MPa})$. The elastic modulus of the mortars is 3247.5 MPa and 7480.1 MPa for lime-based and geopolymeric-based mortars, respectively. The flexural tensile strength of the lime-based mortar obtained from three-point bending test is $6.1 \mathrm{MPa}$, being much larger than the geopolymeric-based mortar (1.12 MPa). The CoVs of the results are relatively small and in the acceptable range of materials testing.

Table 1 Compressive properties of mortars.

\begin{tabular}{lcccc}
\hline \multicolumn{1}{c}{ Specimen } & $\begin{array}{c}\mathrm{E} \\
{[\mathrm{MPa}]}\end{array}$ & $\begin{array}{c}\mathrm{CoV} \\
{[\%]}\end{array}$ & $\begin{array}{c}\mathrm{f}_{\mathrm{c}} \\
{[\mathrm{MPa}]}\end{array}$ & $\begin{array}{c}\mathrm{CoV} \\
{[\%]}\end{array}$ \\
\hline Lime-based mortar & 3247.5 & 14.6 & 12.7 & 11.8 \\
\hline $\begin{array}{l}\text { Geopolymeric- } \\
\text { based mortar }\end{array}$ & 7480.1 & 8.8 & 6.5 & 4.1 \\
\hline
\end{tabular}

Table 2 Mortars tensile flexural properties.

\begin{tabular}{lcc}
\hline \multicolumn{1}{c}{ Specimen } & $\begin{array}{c}\mathrm{f}_{\mathrm{t}} \\
{[\mathrm{MPa}]}\end{array}$ & $\begin{array}{c}\mathrm{CoV} \\
{[\%]}\end{array}$ \\
\hline Lime-based mortar & 6.1 & 15.2 \\
\hline $\begin{array}{l}\text { Geopolymeric- } \\
\text { based mortar }\end{array}$ & 1.23 & 16.8 \\
\hline
\end{tabular}

Tensile tests results

The summary of the results obtained from the tensile tests is presented in Table 3. Higher stiffness, but lower tensile strength is observed in the fabric specimens in comparison to single yarn tests. On the other hand, the tensile strength has increased in the fiber reinforced composite specimens in comparison to the bare flax fabrics. This can be due to the increased integrity of the system due to the mortar presence in the embedded specimens. The stiffness and tensile strength of both composite specimens (lime-based and geopolymeric-based) are similar.

Table 3 Uniaxial tension test results.

\begin{tabular}{lcccc}
\hline \multicolumn{1}{c}{ Specimen } & $\begin{array}{c}\mathbf{E} \\
{[\mathbf{M P a}]}\end{array}$ & $\begin{array}{l}\mathbf{C o V} \\
{[\%]}\end{array}$ & $\begin{array}{c}\mathbf{f}_{\mathbf{t}} \\
{[\mathbf{M P a}]}\end{array}$ & $\begin{array}{c}\mathbf{C o V} \\
{[\%]}\end{array}$ \\
\hline Single yarn & 5913.6 & 18.0 & 193.7 & 3.5 \\
\hline Fabric & 8182.6 & 12.4 & 134.4 & 5.3 \\
\hline FRCM (LM) & 5454.4 & 6.2 & 259.8 & 5.1 \\
\hline FRCM (GPM) & 5636.5 & 13.9 & 237.2 & 18.2 \\
\hline
\end{tabular}


The stress-strain curves of the FRCM specimens are shown in Fig. 8. It should be noted that these curves are obtained based on the total deformation of the specimens consisting of the reinforced and unreinforced parts, see Fig. 3. In general, it can be observed that the limebased composites have higher stiffness after mortar cracking in comparison to geopolymericbased composite. The typical failure mode of the specimens was tensile rupture of the fibers after cracking of the mortar layer. The cracks were uniformly distributed along the specimens, as can be seen in Fig. 9, showing a good stress transfer between the fibers and mortar in both mortar types. As aluminium tabs were used at both ends of the specimens, no fiber slipping occurred during the tensile tests.

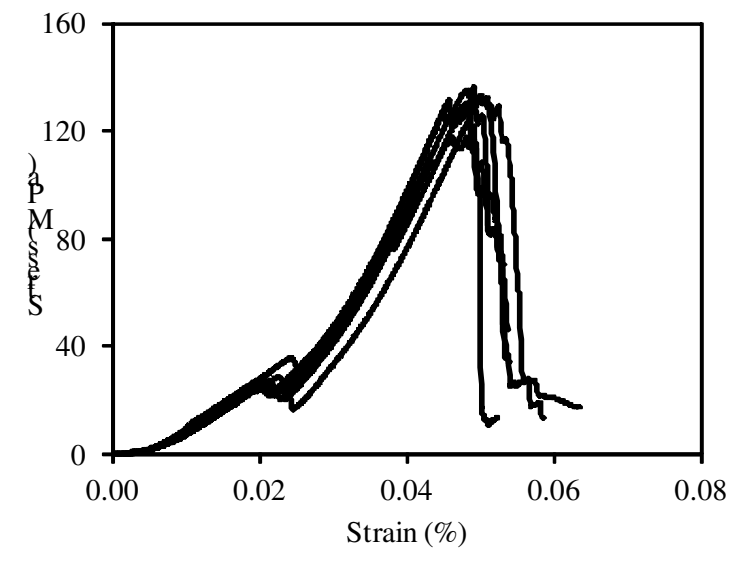

(a)

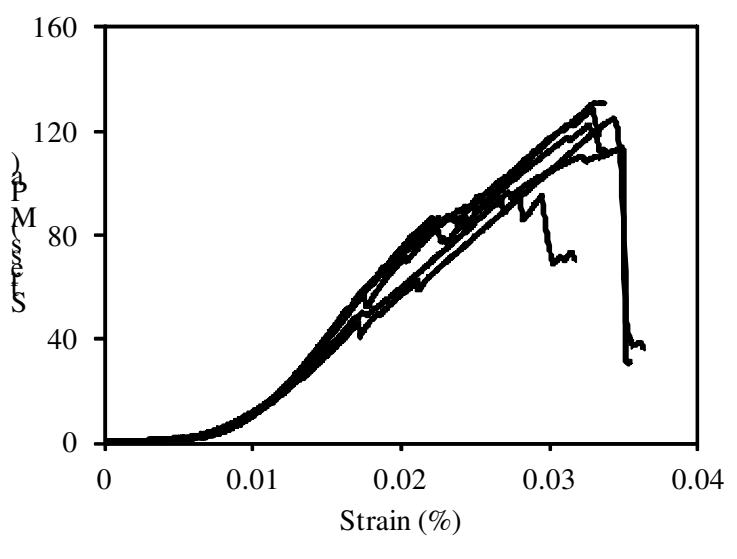

(b)

Fig.8 Tensile stress-strain curves obtained for fiber reinforced mortar specimens: (a) lime-based composite;

(b) geopolymeric-based composite.

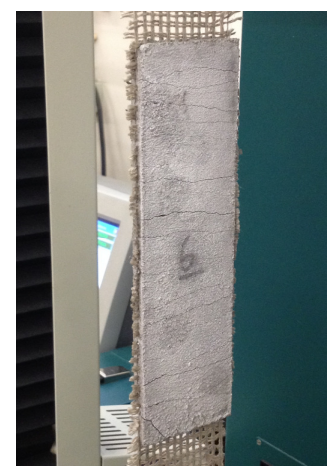

Fig.9 Typical failure mode of the specimens.

\section{Pull-out tests results}

The results from the pull-out tests are presented in Table 4. It can be observed that the matrix type affects significantly the pull-out behavior of the specimens. In the specimens with limebased mortar (FRCM-LM), slipping of the fibers is observed when the bonded length is $50 \mathrm{~mm}$. In the specimens with $100 \mathrm{~mm}$ bonded length, slipping of the fibers occurred in the beginning of the tests followed by the fibers tensile rupture. The maximum pull-out force, $F_{\max }$ in Table 4, has increased from $0.39 \mathrm{kN}$ in the specimens with $50 \mathrm{~mm}$ bonded length to $1.26 \mathrm{kN}$ in the specimens with $100 \mathrm{~mm}$ bonded length. This increase of the maximum pull-out force together with the observed change of failure mode can be the evidence of having the effective bonded length in these specimens between 50 and $100 \mathrm{~mm}$. 
In the specimens with geopolymeric-based mortar (FRCM-GPM), the tensile rupture of the specimens has occurred in both bonded lengths. Therefore, the maximum pull-out force is not expected to not change significantly. The observed small difference between these specimens can be attributed to the materials and specimens variability. According to the observed experimental failure modes, the effective bonded length in the specimens with geopolymericbased mortar is less than $50 \mathrm{~mm}$.

Table 4 Pull-out test results.

\begin{tabular}{ccccccc}
\hline \multirow{2}{*}{$\begin{array}{c}\text { Bond } \\
\text { length } \\
(\mathbf{m m})\end{array}$} & $\begin{array}{c}\text { Fmax } \\
(\mathbf{k N})\end{array}$ & $\begin{array}{c}\text { CoV } \\
(\%)\end{array}$ & $\begin{array}{c}\text { Failure } \\
\text { mode* }\end{array}$ & $\begin{array}{c}\text { Fmax } \\
(\mathbf{k N})\end{array}$ & $\begin{array}{c}\text { CoV } \\
(\%)\end{array}$ & $\begin{array}{c}\text { Failure } \\
\text { mode* }\end{array}$ \\
\cline { 2 - 7 } & 0.39 & 18.85 & $\mathrm{~S}$ & 0.68 & 14.92 & $\mathrm{~S}+\mathrm{R}$ \\
\hline 50 & 1.26 & 15.84 & $\mathrm{~S}+\mathrm{R}$ & 0.82 & 13.85 & $\mathrm{~S}+\mathrm{R}$ \\
\hline 100 & & & & & \\
\hline $\begin{array}{l}\text { S: Slipping of the fibers } \\
\text { R: Tensile rupture of the fibers }\end{array}$ & & & & & \\
\end{tabular}

\section{CONCLUSIONS}

The results of tensile and pull-out bond tests on flax fiber reinforced mortar specimens were presented in this study. Two different matrices, namely a pozzolanic lime-based mortar and a geopolymeric-based mortar, were used as innovative matrices. The tensile tests were performed on single yarn, fabrics and fiber reinforced mortar specimens. Fiber reinforced mortar specimens showed higher tensile strength in comparison to the bare fabrics due to the presence of mortar. The failure occurred in the specimens due to tensile rupture of the fibers after a uniform development of tensile cracks along the mortar layers. The pull-out tests showed that the effective bond length in the specimens with lime-based mortar is between $50 \mathrm{~mm}$ and $100 \mathrm{~mm}$, although this value is less than $50 \mathrm{~mm}$ in case of geopolymeric-based mortar. The maximum pull-out force in the specimens was $1.26 \mathrm{kN}$ for specimens with $100 \mathrm{~mm}$ bonded length embedded in lime-based mortar.

\section{ACKNOWLEDGMENTS}

The first author gratefully acknowledges the funding by Fundação para a Ciência e a Tecnologia (FCT), under the grant SFRH/BPD/92614/2013. The assistance of the technicians of the Structures Laboratory (LEST), where the experimental work took place, is also acknowledged.

\section{REFERENCES}

Carozzi FG, Milani G, Poggi C, Mechanical properties and numerical modeling of Fabric Reinforced Cementitious Matrix (FRCM) systems for strengthening of masonry structures. Composite Structures, 2014, 107, p.711-25.

Codispoti R, Oliveira DV, Olivito RS, Lourenço PB, Fangueiro R, Mechanical performance of natural fiber-reinforced composites for the strengthening of masonry. Composites Part B, 2015, accepted for publication.

D'Ambrisi A, Feo L, Focacci F, Experimental analysis on bond between PBO-FRCM strengthening materials and concrete. Composites Part B, 2013, 44(1), p. 524-32. 
De Felice G, et al., 2014. Mortar-based systems for externally bonded strengthening of masonry. Materials and Structures, 2014, 47(12), pp.2021-2037.

EN 1015-11,2007. Methods of test mortar for masonry- Part 11: Determination of flexural and compressive strength of hardened mortar.

Carozzi FG, Milani G, Poggi C, Mechanical properties and numerical modeling of Fabric Reinforced Cementitious Matrix (FRCM) systems for strengthening of masonry structures. Composite Structures, 2014, 107, p.711-25.

Carozzi FG, Poggi C, Mechanical properties and debonding strength of Fabric Reinforced Cementitious Matrix (FRCM) systems for masonry strengthening. Composites: Part B, 2015, 70, p.215-30.

Sueki S, Soranakom C, Mobasher B, Peled A, Pullout-slip response of fabrics embedded in a cement paste matrix. Journal of Materials in Civil Engineering, 2007, 19(9), p.718-27. 